\title{
Fine Sprays for Disinfection within Healthcare
}

\author{
G.G.Nasr ${ }^{1, *}$, A. Whitehead ${ }^{2}$ and A.J.Yule ${ }^{1}$ \\ 'Spray Research Group (SRG), Engineering Research Centre (ERC), \\ School of Computing, Science and Engineering (CSE), \\ University of Salford, Manchester M5 4WT, United Kingdom \\ 2Hughes Safety Showers (HSS) Ltd, \\ Whitefield Road, Bredbury, Stockport, SK6 2SS, United Kingdom
}

\begin{abstract}
Problems exist worldwide with Hospital Acquired Infections (HAl's). The Spray Research Group (SRG) have been working with relevant industries in developing a product which can provide a delivery system for treatment chemicals for surfaces, including the design and testing of a novel SpillReturn Atomiser (SRA) for this purpose. A comprehensive description of this atomiser has already been given. This paper reports on a new application of this atomiser and discusses the problem of spray coating for disinfection that has been considered very little in previous work. The related spray coating performance tests in developing the product are thus provided. The experimental work includes determining the required spray duration and the coverage area produced by different sprays, including the analysis of the effects of atomiser positions, configurations, and the required number of atomisers. Comparison is made with the efficacy of an ultrasonic gas atomiser that is currently used for this purpose. The investigation has found that the utilisation of fine sprays $\left(10 \mu \mathrm{m}>D_{32}>25 \mu \mathrm{m}\right)$ at high liquid pressure $(<12 \mathrm{MPa})$ and low flow rates $(<0.3 \mathrm{l} / \mathrm{min})$ is suitable for surface disinfection in healthcare applications (i.e. MRSA, VRSA etc).
\end{abstract}

Keywords: Fine spray, Disinfection, Healthcare, Spill return atomiser

\section{INTRODUCTION}

Non-ideal cleanliness and hygiene practice has led to an increase in infection rates with subsequent increases in deaths and illnesses associated with Hospital Acquired Infections (HAI's). The acronym MRSA (Methicillin Resistant Staphylococcus Aureus) has become synonymous with the problems as the appearance of organisms resistant to antibiotics have meant that HAI's involving MRSA have in some instances led to patient mortality. Other infections have also begun to appear including VRSA (Vancomycin Resistant Staphylococcus Aureus) and Clostridium Difficile. Costs associated with extra treatment and extended hospital stays for patients acquiring an infection during their hospitalisation are said to be significant, not to mention the human and social effects. It is estimated by the National Audit Office and the Health Service Journal, [1] that "at any one time 9 per cent of in-patients have a hospital acquired infection within the UK." This works out at approximately 300,000 patients a year that acquire one or more infections. This may not sound significantly high; especially when annually over 3.7 million people are admitted to

*Corresponding author: g.g.nasr@salford.ac.uk Associated Web site: http://www.cse.salford.ac.uk/srg 
hospital each year, for both long and short term visits. However several reports, such as the Health Service Journal's article on Infection Control, published on 2005 [2] and the Department of Health's article on the fight against HAI's [3], estimate that approximately 5000 people a year die due to hospital acquired infections or as an indirect result of them. It is also estimated that the extra cost to the NHS (National Health Service) per year for treating hospital acquired infections including after care, amounts to over $£ 2$ billion in England alone. Most patients who contract a HAI spend over twice as much time in hospital recovering as they would of if they had not contracted a HAI. This extra time costs money in terms of bed space, food, care and nursing.

It is therefore proposed that products can be developed using fine sprays, $10 \mu \mathrm{m}<D_{32}<25 \mu \mathrm{m}$ say, where D32 is the Sauter Mean Diameter (SMD) of the drops, which can help tackle problems with HAI's by providing a guaranteed clean environment for patients and staff. This is achieved by providing an effective and efficient delivery system for specified disinfectant agents which have been proven to be able to kill organisms which may lead to infection. These disinfectants work by coming into contact with the organisms present on a surface, and remaining in contact for a certain length of time (typically minutes) so as to kill the harmful organism present.

So why use a fine spray for disinfection applications? Using a fine spray for disinfection applications has many advantages over a conventional spray and cloth system. First of all there is no requirement to use a cloth [1-3] to apply the disinfectant. It is known that often the fibres within cleaning appliances such as cloth's can actually hide bacteria and infections and ultimately spread them round when used for cleaning purposes. This is especially the case when cleaning appliances are not regularly cleaned or replaced. The fine spray technology concept works on the idea that the droplets produced are very small $(\leq 25 \mu \mathrm{m})$ and can be adequately applied to a surface to give a good even coverage area. Also by using the spillreturn atomiser in the production of fine sprays, the required droplet size can be determined to give an adequate contact time for any disinfectant applied to be effective but also evaporate away quickly to leave no residue behind. This also means that the spray is not "wet", (i.e. leaves a wet surface that doesn't dry quickly and either has to be wiped up or takes a long time to dry), on application, so it is safe for use on people as well as on objects and surfaces. By knowing the surface coverage area sprayed by the atomiser, a system can be devised where an operator can spray an object or area and achieve full coverage quickly and easily. Furthermore by using a fine spray, the small droplets and ease of moving through the surrounding medium, allows the disinfectant spray to reach hard access areas, such as behind a bed or underneath equipment. This is crucial in disinfecting an area as full coverage can be achieved.

The authors have cooperated with concerned public and private bodies, led by a major company in Manchester, UK, in developing a product which can provide a delivery system for such a chemical, including the design and testing of a new miniature high pressure spillreturn atomiser $[4,5]$. In summary, the design of the atomiser incorporated a swirl chamber within the atomiser to create a fine spray at the atomiser exit. The atomiser also has a spillreturn orifice that allows a high pressure flow into the atomiser but with a low volume flow rate. Up to $85 \%$ of the liquid arriving at the atomiser can be returned to the tank for usage later. Therefore a system utilising this atomiser design could be used for a substantial time without the requirement for refilling the disinfectant or wasting excess fluid. Minimising the excess fluid is also crucial as this would have to be dealt with and would normally involve using a cloth or mop to remove it, in turn re-introducing a bacteria source that the system is trying to eliminate. Moreover allowing the system to be used for a substantial time makes it easier to keep track of progress of disinfection but also makes the system more appealing 
when considered from a practical usage point of view. The utilisation of such a system may be used in a hospital environment as well as for decontamination purposes in Chemical, Biological, Radiological and Nuclear environments (CBRN) [6].

Currently the company produces a successful "HUSA" portable surface coating disinfection system [7] that uses "Sonicore" $052 \mathrm{H}$ ultrasonic gas atomisers, using portable compressed air bottles. An aim is to confirm that the spill-return atomisers can produce similar sprays and surface coverage. A new product incorporating the new atomisers would be complementary in that although a mains power supply connection would be required, to power the pump; neither compressed air bottles nor a pressurised liquid reservoir would be required.

This paper introduces the problem and outlines the spray performance tests in developing the product using the previously reported high pressure spill-return atomiser [8-10]. The experimental work includes: measuring the ideal spraying time and the coverage area as a function of atomisation conditions and examining the effects of atomiser positions, configurations, and the required number of atomisers. The results are compared to the data obtained from the company, HUSA system.

Previous experiments with the existing Hughes Ultrasonic Atomiser (HUSA) system showed that it successfully coated surfaces (walls, furniture etc.) using spray flow rates of the order $0.1 \mathrm{l} / \mathrm{min}$ and drop sizes with $\mathrm{D}_{32}<20$ microns. Higher flow rates or larger drop size could result in excessive local surface wetting and poor coverage. If flow rates are too low, coating times are excessive and when drops are too fine they may not penetrate to the surface, being instead carried away with the air flow in the room, induced by the compressed gas jet from the atomiser. Investigation of high pressure swirl atomisers, with spill-return, has shown [8] that at supply pressure of the order 10MPa, they can produce flow rates similar to the ultrasonic atomiser and also similar drop sizes. Without spill-return the flow rate can be excessive, whilst the addition of spill-return reduces spray flow rate with little effect on drop size. The "spilled-off" liquid is not wasted because it is returned to the liquid reservoir.

The main contribution of the present work, beyond what have previously been reported in [5 and 8], is thus to be able to assess the performance and functionality of a simulated mobile unit for the purpose of a disinfection system within healthcare environment using the SRA (Spill-Return Atomiser).

The prime objectives of this study are:

i. To assess the performance of the disinfection system using simulated disinfection apparatus.

ii. To carry out a comprehensive analysis of the coating process utilising the apparatus. Emphasis will be placed upon droplet interaction with the target surface and the amount of liquid deposited upon a given surface area over a given spraying time period.

iii. To provide a broad understanding of the spray characteristics that are needed to ensure the disinfection system imparts the required spraying time and coverage area, as function of atomisation condition and to examine the parametric effects of SRA atomiser positions, configurations and the atomiser numbers.

iv. To compare the results and findings of this experimental investigation with those data that obtained from the HSS, HUSA system.

v. Based on the information that obtained in (ii), (iii) and (iv), a recommendation on the suitability of the atomiser and disinfection system, prior to the production of a 'novel' prototype unit, for providing full spray coverage, within a room based environment for healthcare applications, will be made 


\section{METHODS}

\subsection{EXPERIMENTAL APPARATUS AND PROCEDURE}

Figure 1 shows the test apparatus, which has previously been described in detail in [8], uses one or more spill-return atomiser attached to an aluminium pillar that was fixed to a portable trolley. An unpressurised liquid reservoir was mounted on the trolley together with a high pressure pump, manufactured by Interpump Group and capable of producing up to $15 \mathrm{MPa}$, at a flow rate of $8 \mathrm{l} / \mathrm{min}$. A pressure gauge, distribution block, and a high pressure hydraulic pipe were used for delivery of the liquid from the pump to the atomiser. Water was used since it has similar physical properties as most disinfection solutions likely to be used. During commercial operation the fluid supplied will be a solution of decontamination agent, Sterichelle, and water. The recommended concentration for this solution is 65 parts water to 1 part Sterichelle. At these small concentrations it was sufficient for only water to be used in the testing of the atomiser for coating performance.

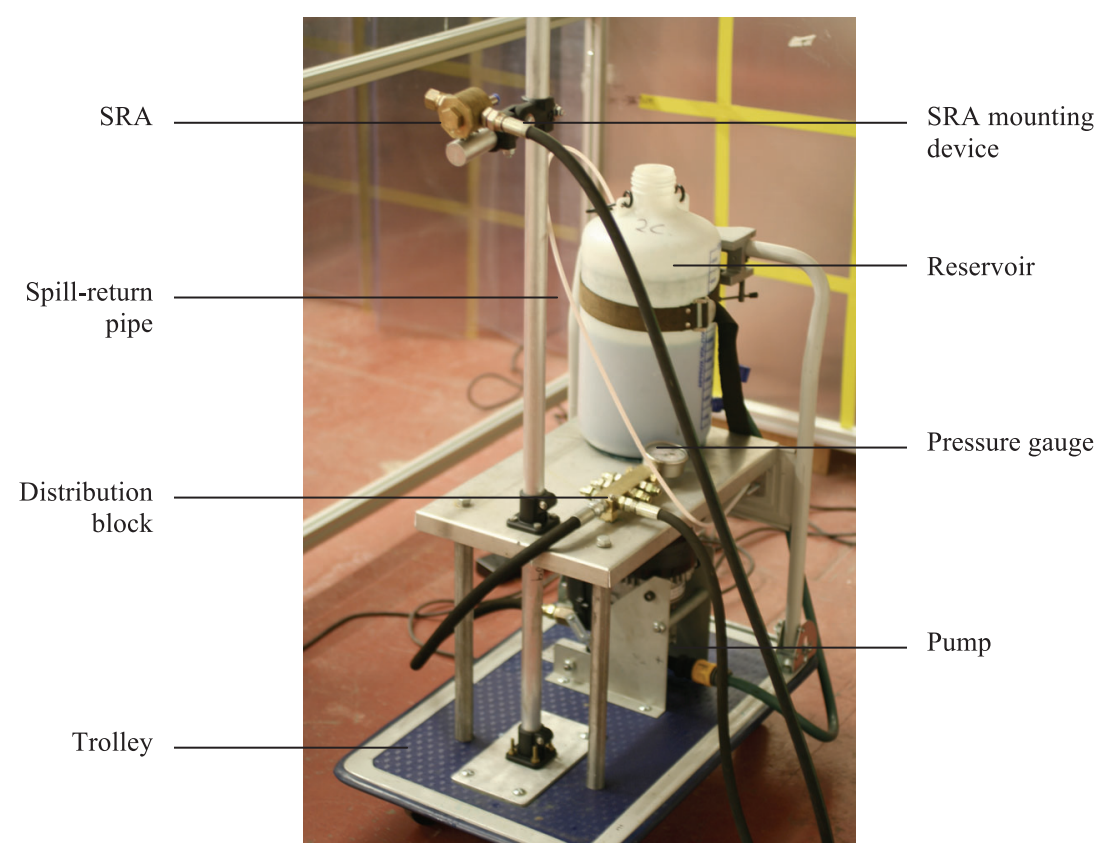

Figure 1. Simulated SRA (Spill-Return Atomiser) disinfection system apparatus

All the test results reported here are for a maximum spray flow rate of $0.245 \mathrm{l} / \mathrm{min}$ and maximum supply pressure of $9 \mathrm{MPa}$, using a $0.3 \mathrm{~mm}$ diameter exit orifice. It was found that this was the optimum supply pressure and flow rate which, thus, provided the required fine sprays and uniform surface coating. Since the liquid droplet size reduces with pressure, hence producing coarse sprays and poorer coverage. An additional objective of this study was to match and enhance the findings of the system in terms of coating with those obtained from HUSA portable surface coating disinfection system.

A more detailed description of the spill-return atomiser and its performance has been provided in other publications [5, 8]. Figure 2 shows a schematic diagram of the spill-return atomiser used throughout this work. The actual geometry used was selected to give small spray angles $\left(<40^{\circ}\right)$ and thus good penetration. A spill-return pipe returns the liquid from the 


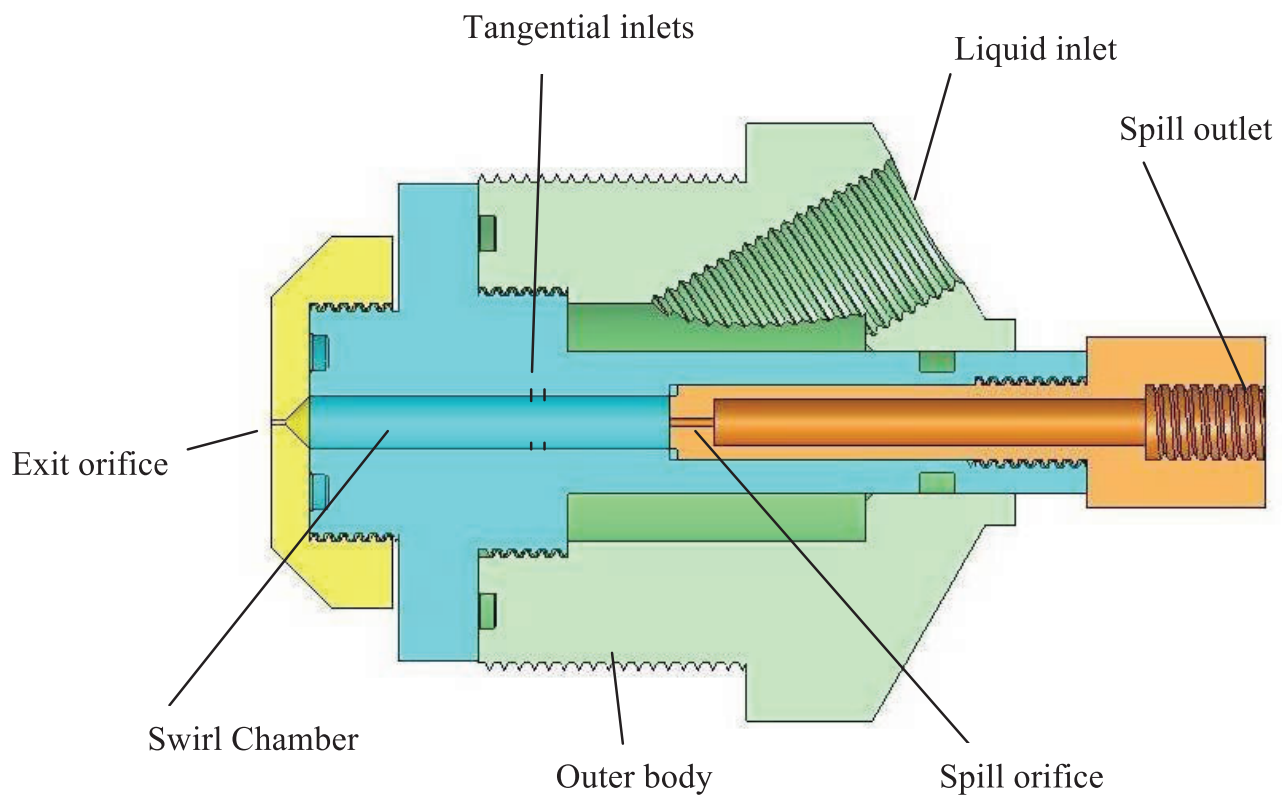

Figure 2. Schematic diagram of a spill-return atomiser

spill orifice to the tank. The atomiser was mounted on an adjustable slider bracket attached to the pillar. It should be noted that a zero (or no) spill case was also tested by replacing a blanking plug at the spill outlet of the atomiser. This enabled the effectiveness of the spillreturn atomiser over the zero spill atomiser to be closely examined.

For "twin atomiser trials" a second identical atomiser was attached to the pillar rig and fed via the liquid distribution block which ensured that equal flow rates were fed to each atomiser. All tests were conducted within a simulated hospital room, referred to here as the 'test chamber' (Dimensions: Length $=3.7 \mathrm{~m}$, Width $=2.5 \mathrm{~m}$, Height $=2.6 \mathrm{~m}$ ). Common HAI propagating locations are also door handles, keyboards, ventilator and incubators surface. The test chamber was made of four different wall materials: brushed stainless steel, clear glass, plastic (PVC) and laminated plywood. The ceiling was made of wood and the floor was concrete. This gave the potential for investigation of the efficacy of disinfection for different surfaces which are commonly found within healthcare environments (i.e. glass: windows, laminated plywood: bedside cabinets, stainless steel, and medical apparatus). The test chamber was maintained at a temperature, $20 \pm 2^{\circ} \mathrm{C}$, since variation in ambient temperature would affect the rate of evaporation of the spray droplets before wall impact. A high resolution digital camera with a "macro" lens (Cannon EOS 350D) was used to give close up views of the coated surface. Each image captured, was set to a picture definition of $2496 \times 1664$ pixels at the focal length of $300 \mathrm{~mm}$. A Laser Particle Sizer (LPS) was utilised for determining the initial drop size distributions [8].

\section{ON THE COATING PROCESS}

There is remarkably little previous work on the spray coating of surfaces that is directly relevant to the present disinfection application. Of interest is the body of research in the combustion field [11] that is concerned with the behaviour of droplets on impacting at a solid surface. Bai and Gosman [12] considered this situation in detail with the aim of developing 
empirical submodels for different regimes of drop impact as shown schematically in Figure 3. They split the situation into two main phases: (1) when the wall is dry and (2) when the wall is wet. Clearly both situations apply here and for the dry wall case the regimes of droplet adhesion to the wall and droplet splashing was described by a critical Weber number, Wec, such that:

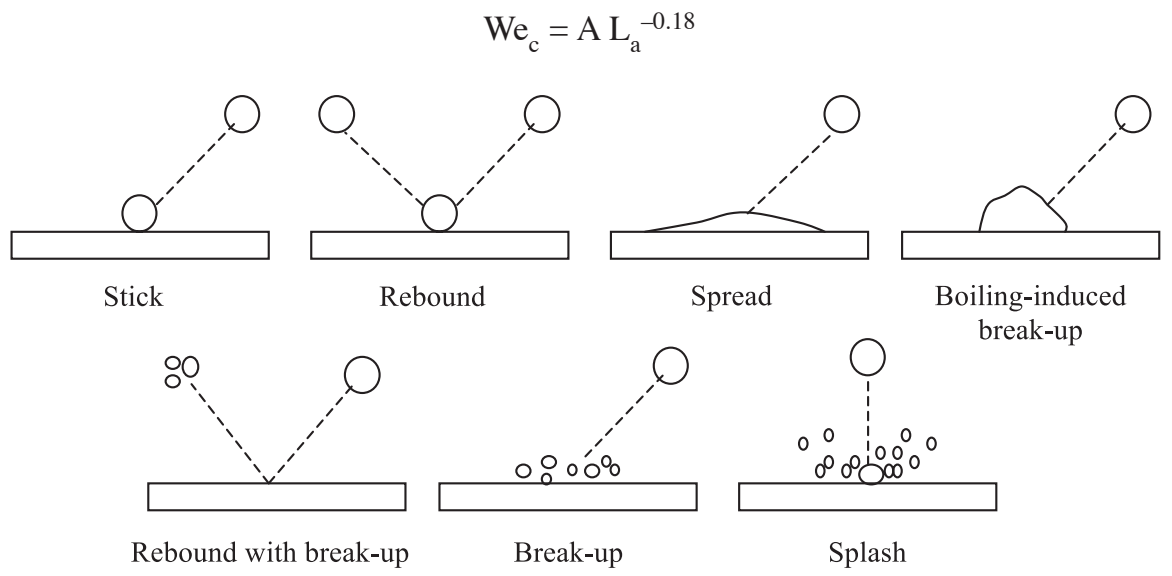

Figure 3. Different modes of drop impaction and subsequent drop behaviour [8]

Weber number is We $=\rho \mathrm{U}^{2} \mathrm{D} / \sigma$ and the Laplace number is $\mathrm{L}_{\mathrm{a}}=\sigma \rho \mathrm{D} / \mu^{2}$, where $\rho$ is liquid density, $\mathrm{D}$ is drop diameter, $\mathrm{U}$ is the velocity component of the drop perpendicular to the wall and $\sigma$ is surface tension. The empirical coefficient A depends upon the surface roughness and a table of values was provided. A value of $\mathrm{A}=1400$ corresponds to approximately $10 \mu \mathrm{m}$ roughness.

Clearly in the present process, adhesion is required to dominate drop impacts and this is favoured by the smaller droplets and slower, softer sprays. However there are limitations in the case of very small droplets, one limitation being the need to avoid excessive "drift" of droplets away from the main spray, for the droplets to be carried into the surrounding atmosphere giving poor target efficiency and also providing an inhalation hazard. Sub- $10 \mu \mathrm{m}$ diameter droplets could provide such a hazard. In addition, when the wall is wet, or partly wet, there is a likelihood of smaller, slower droplets rebounding from liquid already on the surface. This boundary between rebounding and attaching and splashing on a wetted surface, was defined [12] by a second critical Weber number:

$$
\mathrm{We}_{\mathrm{c} 2}=5
$$

These relationships can be used to show that the relatively "soft" sprays, with narrow drop size distributions, produced by the spill-return atomisers, are ideal for coating process. For example [2], typically $90 \%$ of the volume of the spray is in drops between $10 \mu \mathrm{m}$ and $50 \mu \mathrm{m}$ and typically mean drop velocity is around $5 \mathrm{~m} / \mathrm{s}$ at $1 \mathrm{~m}$ downstream. From equation (1) the critical Weber number for a $50 \mu \mathrm{m}$ water droplet is 1100 and a $5 \mathrm{~m} / \mathrm{s}$ drop of $50 \mu \mathrm{m}$ has a Weber number of 17 , with a surface tension of $0.074 \mathrm{~ms}$ [12], so that there is no chance of splashing. For the $10 \mu \mathrm{m}$ droplets the value of Weber number is 3.7, so that there is some chance of rebounding from an already wet surface. 


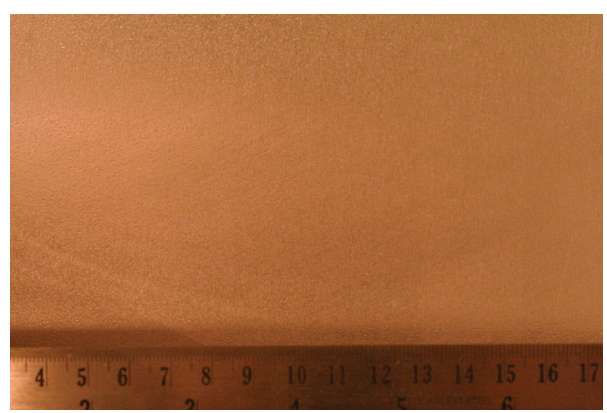

(a)

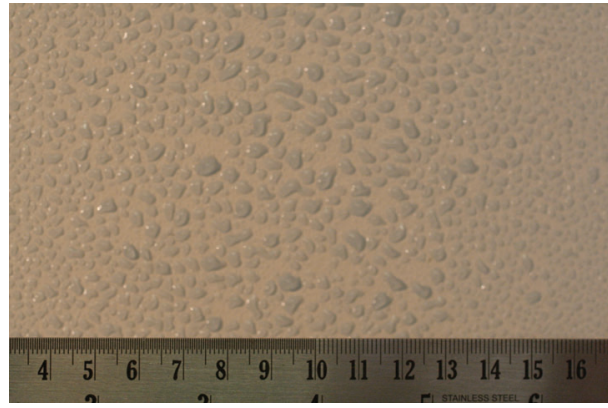

(c)

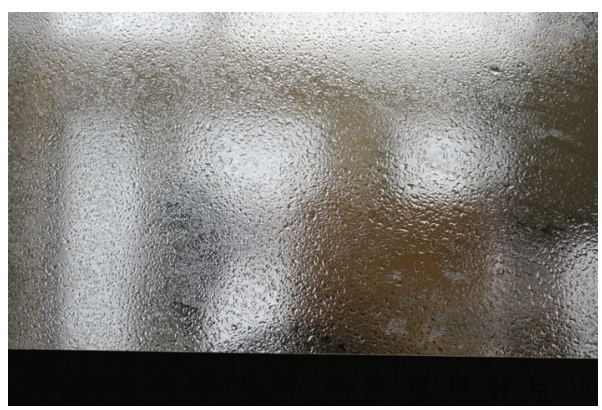

(b)

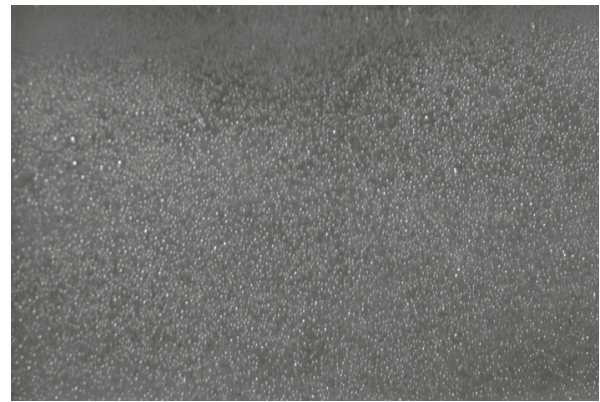

(d)

Figure 4 Typical close up view of the coalescence of fine droplets formed by impacting spray droplets on (a) brushed stainless steel, (b) PVC, (c) varnished plywood and (d) glass surface at atomiser angle $45^{\circ}$

A difficulty is to define when a surface has reached an ideal fully coated situation. It is found that for low viscosity liquids such as water, and which do not "dry" in the manner of paint coatings, there is tendency for impacted droplets to coalesce into isolated larger flattened "lamella", this particularly being the case for polished waxed or varnished surfaces. This is illustrated by Figure 4 which shows the four surfaces (brushed stainless steel, plastic (PVC)), varnished plywood and clear glass) after $134 \mathrm{sec}$ spraying at a distance of $2 \mathrm{~m}$, using the atomiser at $9 \mathrm{MPa}$ and flow rate $0.245 \mathrm{l} / \mathrm{min}$. Although the impacting drops are in the diameter range $10 \mu \mathrm{m}-55 \mu \mathrm{m}$, the coalescence phenomenon results in quite evenly distributed lamella with typical diameter $1-4 \mathrm{~mm}$. In fact the area between these lamella have experienced impaction and surface tension effects are drawing in smaller drops to the larger lamella. During spraying a point is reached when adjacent larger lamella coalesces and, for a vertical wall, gravitational forces overcome surface tension so that "streaking" occurs. For this investigation this time of onset of streaking has been defined as the ideal spraying time, or "required spray duration" for local wall coverage. This is illustrated in Figure 5. The definition of ideal spraying time is justified for two reasons: (1) spraying for a time beyond this streaking onset gives liquid wastage and excessive wetting of the lower parts of walls and the floor, and (2) the time of occurrence of this streaking is easily recognised and also coincides with wetting occurring for the complete surface locally.

A further important parameter is the coverage area, or "coverage" for the spray, for a 


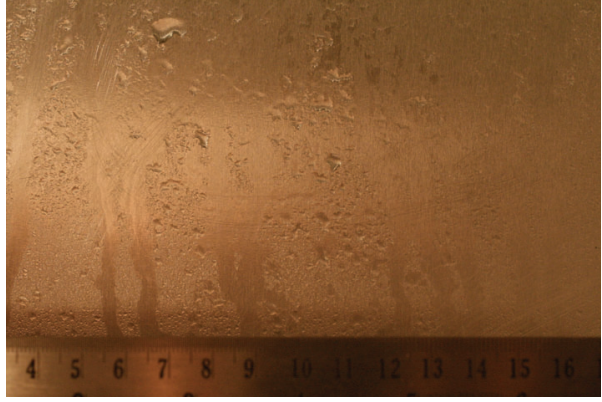

(a)

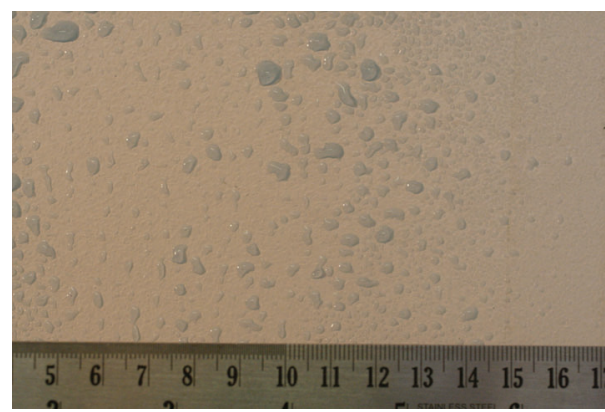

(c)

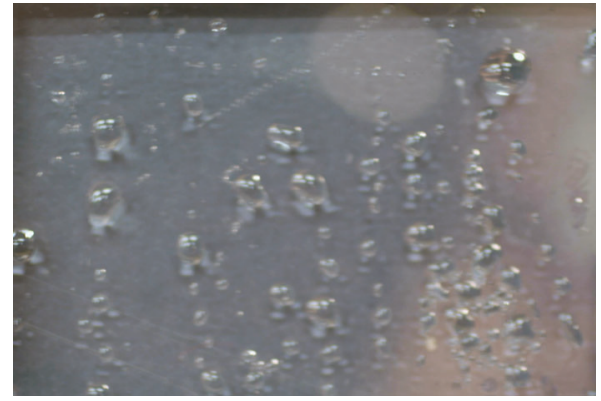

(b)

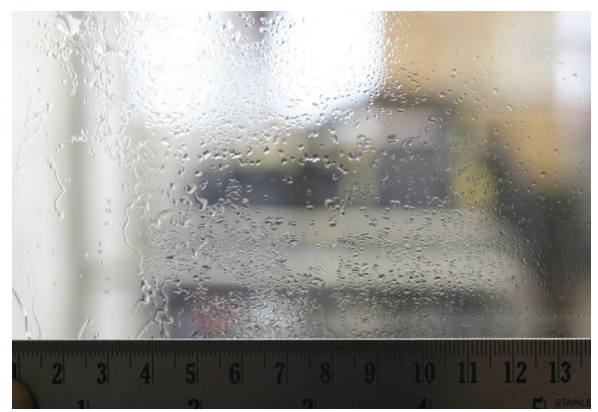

(d)

Figure 5 Typical view on point of streaking (optimum condition) on (a) brushed stainless steel, (b) PVC, (c) varnished plywood and (d) glass surface at atomiser angle $45^{\circ}$

given spraying time. For this investigation the coverage was measured by visually inspecting the impacted surface, after the spray was switched off, and measuring the surface area for which streaking could be seen to be occurring.

\section{RESULTS AND DISCUSSION}

\subsection{DISTANCE AND REQUIRED SPRAY DURATION}

Tests were conducted using a range of distances, $1 \mathrm{~m}<\mathrm{d}<3.0 \mathrm{~m}$, from the atomiser exit perpendicular to the chosen surface, and also for different atomiser heights above the floor. Various spill orifice diameters, including a zero spill ('blank') atomiser, were also tested. Because of the fine nature of the sprays and the relatively narrow initial angles, the sprays were of the "solid cone" shape at impaction giving a relatively uniform spray patternation in the central impact zone. Tests used a maximum spray flow rate of $0.55 \mathrm{l} / \mathrm{min}$ and maximum supply pressure of $12 \mathrm{MPa}$, with most cases using a $0.3 \mathrm{~mm}$ diameter exit orifice.

Figure 6 shows the variation of required spray duration for optimum coverage, with distance from the atomiser exit to the vertical surface, for a horizontal spray orthogonal to the surface. The zero-spill-return case, shown in Figure 6, was found to rapidly lead to streaking, the flow rate of the impacting spray being too high for controllability of spray duration. For $1 \mathrm{~m}<d<3 \mathrm{~m}$ and with spill orifice diameters $0.4 \mathrm{~mm}$ and $0.5 \mathrm{~mm}$, full coverage of the impaction area could be obtained with streaking just commencing. For these cases [8] the 


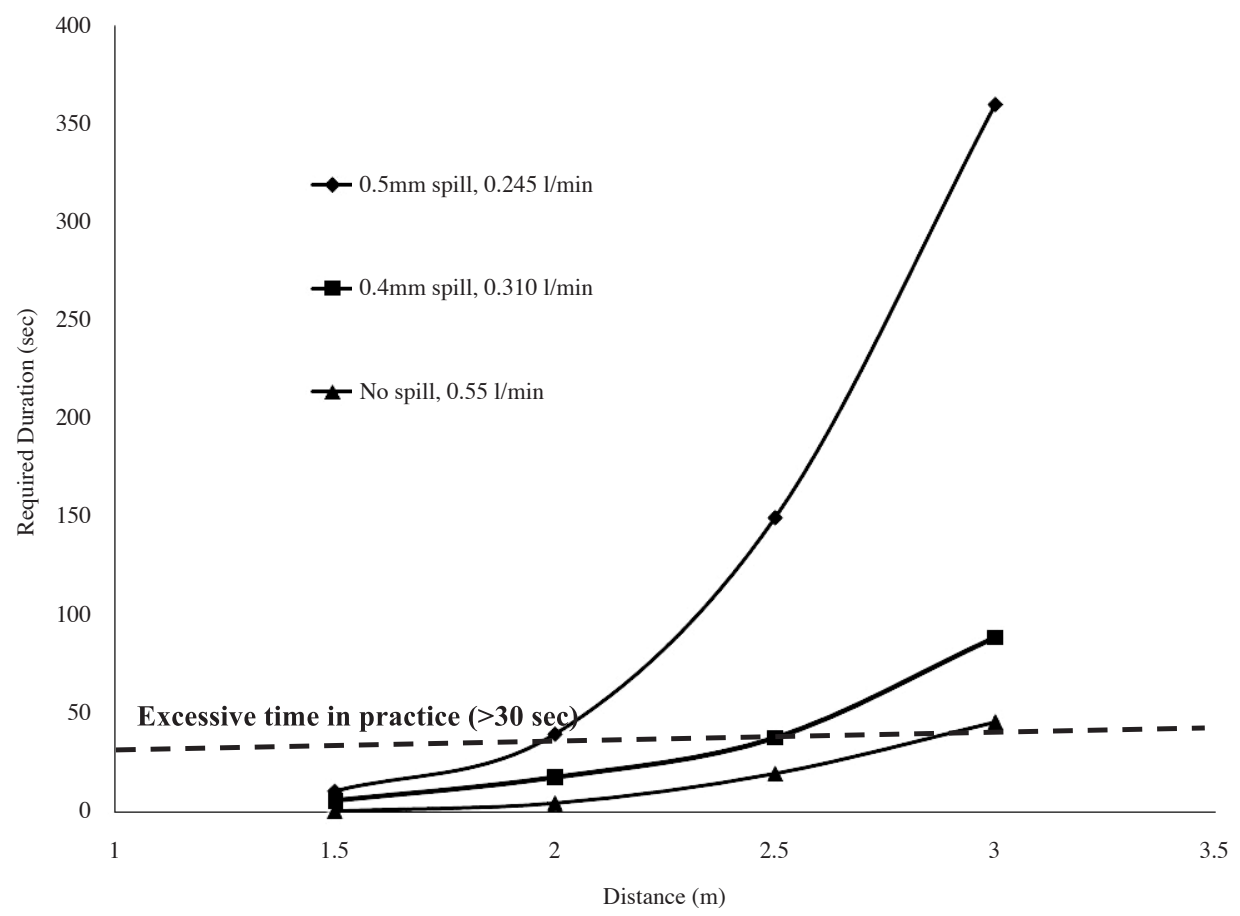

Figure 6. Variation of required spray duration with distance, supply pressure 9MPa, horizontal spray, plastic (PVC) surface

drop sizes were, $\mathrm{D} 32=18 \mu \mathrm{m}$, with spray cone angle $34^{\circ}$, and $\mathrm{D}_{32}=19 \mu \mathrm{m}$, with spray cone angle $46^{\circ}$, respectively. For the no spill case the drop size found to be, D32 $=15 \mu \mathrm{m}$ with the spray cone angle $22^{\circ}[8]$.

As can be seen in Figure 6, at a distance above approximately $2 \mathrm{~m}$ with spill diameter of $0.5 \mathrm{~mm}$ the spray time duration shows a rapid increase which was found to be due to the slower penetration and widening of the spray. Up to $2 \mathrm{~m}$ to $2.5 \mathrm{~m}$ found to be an optimum distance for uniform coating. When the system was operated with spill diameter orifice of $1 \mathrm{~mm}$, giving a spray flow rate $0.075 \mathrm{l} / \mathrm{min}$, it was found that a high proportion of the spray droplets did not penetrate to $2 \mathrm{~m}$ and the larger drops were mostly deposited on the floor as opposed to on the wall. Moreover, for the no spill case shown in Figure 6, a high spray flow rate was experienced by the corresponding surfaces which resulted on fast and uncontrollable coverage. This is particularly the case when operating with the handheld system, with no spill atomiser, in which the duration becomes too short for coherent coating.

Figures 7 and 8 shows the variation of required spray duration with distance with an atomiser at different heights $1.2 \mathrm{~m}, 1.6 \mathrm{~m}, 2.0 \mathrm{~m}$ and $3 \mathrm{~m}$ with supply pressure at $9 \mathrm{MPa}$. The case with two atomisers simultaneously, at $0.8 \mathrm{~m}$ apart and at the total height of $2 \mathrm{~m}$ from the floor, is also typically shown. In the cases shown, $0.5 \mathrm{~mm}$ spill diameters were used, with exit orifice diameter of $0.3 \mathrm{~mm}$. At a distance of $3.0 \mathrm{~m}$ the required time to obtain uniform coverage with a single atomiser could range from 270 seconds to over 360 seconds. In practice times above 30 seconds are not probably useful, as typically indicated on Figure 6. The results generally showed that as the height of the atomiser increases the required spray duration decreases. The effect of duration as a function of height may, arguably, be due to 


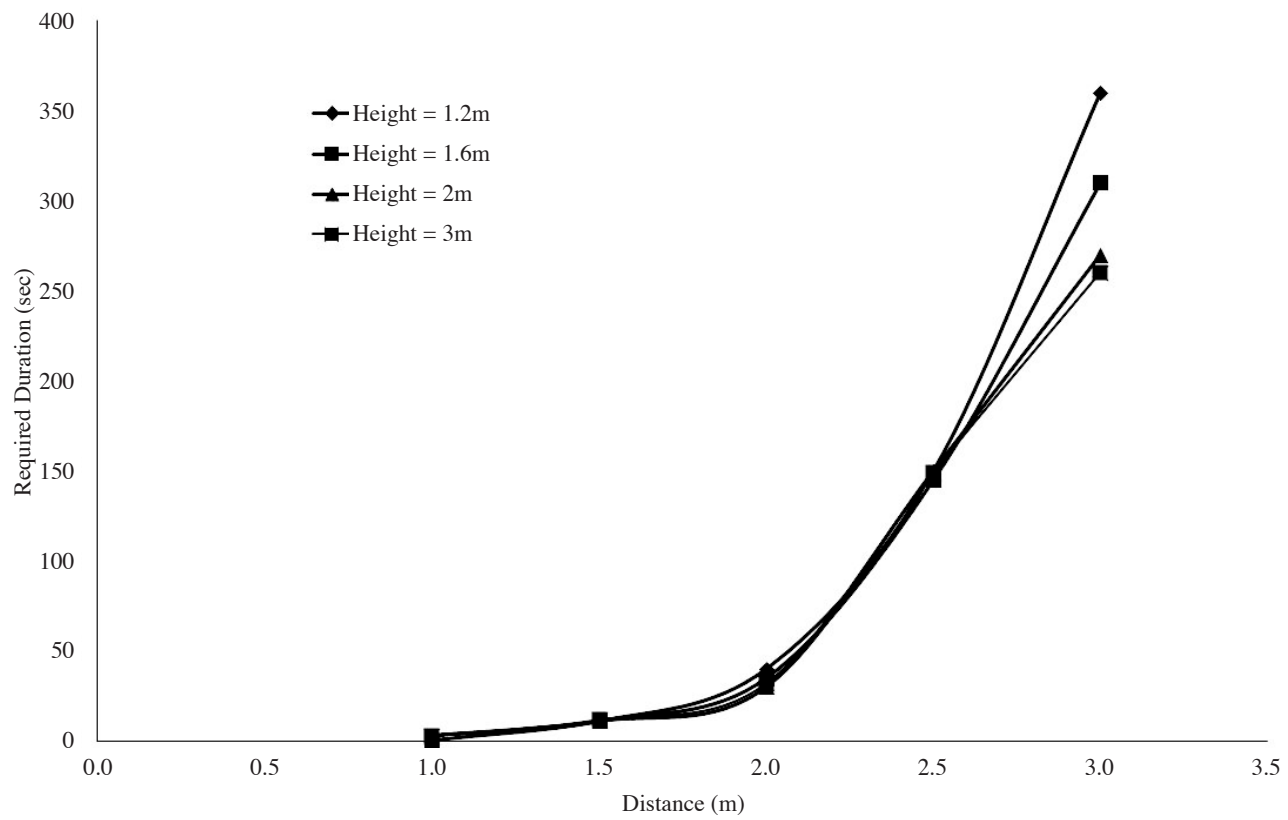

Figure 7. Variation of required spray duration with distance at different heights relative to the plastic (PVC) surface with one atomiser, diameters: $0.5 \mathrm{~mm}$ spill and orifice $0.3 \mathrm{~mm}$, supply pressure $9 \mathrm{MPa}$

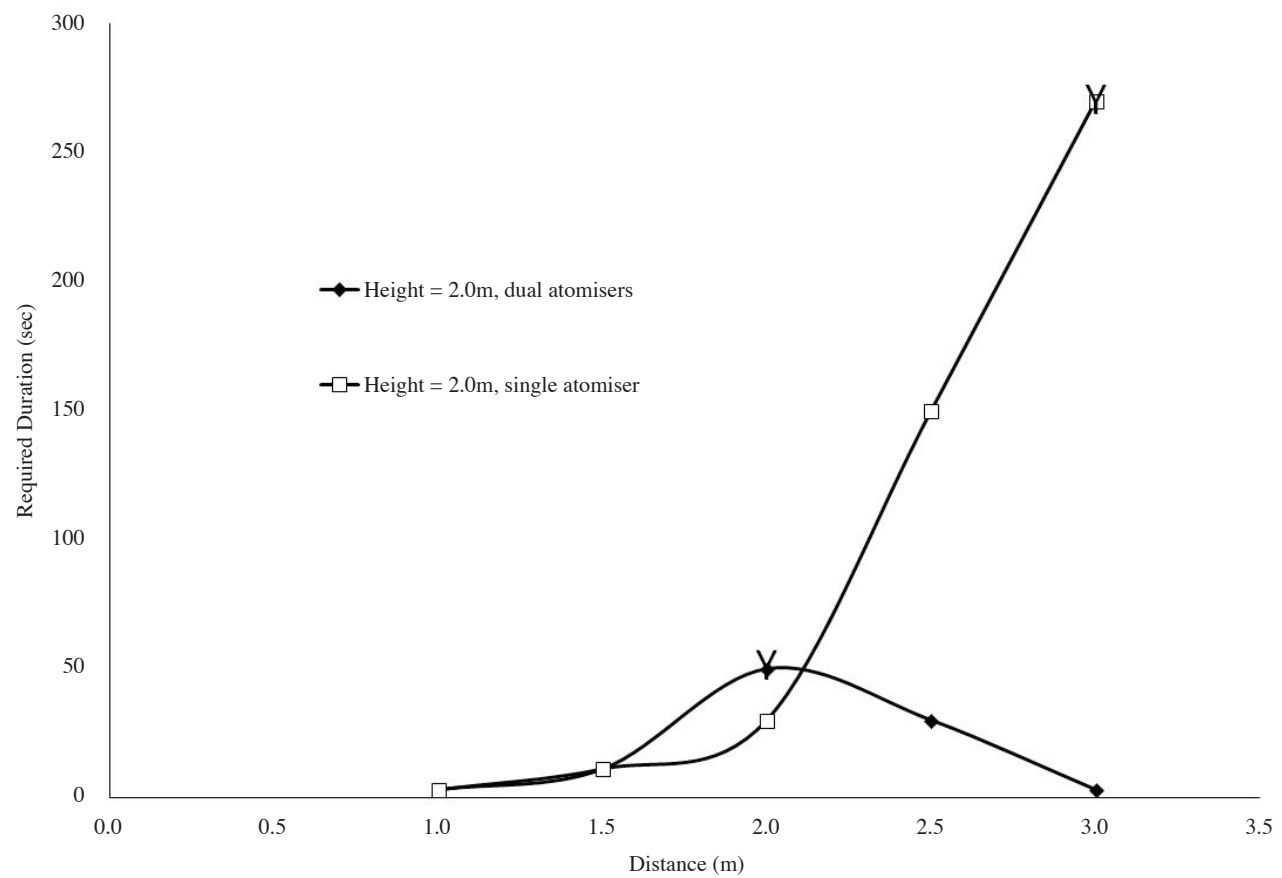

Figure 8. Comparison of required spray duration with distance, relative to the plastic (PVC) surface, for one atomiser and dual atomiser, at typical height of $2 \mathrm{~m}$, diameters: $0.5 \mathrm{~mm}$ spill and orifice $0.3 \mathrm{~mm}$, supply pressure $9 \mathrm{MPa}$ 
effect of gravity on the drops which could also depend upon the droplet size. However, it is believed that, in this study, the effect of air entrainment at different height of atomiser could be prevailed over that of the droplet size. Although future studies along with a suitable mathematical model will include these effects prior to the production of the prototype system. It is also noted from Figure 8 that when two atomisers are used together at up to $2 \mathrm{~m}$ from the wall, the required time duration is a little higher, than for a single atomiser at either height independently. However as the distance increases beyond $2.0 \mathrm{~m}$ with dual atomisers, the required spray time duration rapidly decreases. As described below the reason is partly due to the entrainment of the air into the two sprays being stronger than for one spray, giving a focusing of the central spray zones, i.e. higher liquid mass flux locally than for a single spray. In addition, use of two sprays increased turbulence and convection patterns in the chamber and this led to more fine droplets being moved randomly round the chamber and deposited elsewhere rather than being directed and deposited onto the target area at the wall.

\subsection{SPRAY COVERAGE AREA}

Figure 9 shows schematically the density of the impacted drops deposited on the respective surfaces for single sprays with the atomiser axis orthogonal to the surface and also at an angle of $30^{\circ}$ relative to the perpendicular. The area of uniform coverage produced by the atomiser is similar to the shaded black in Figure 8 which it is found to be roughly elliptical when the atomiser is set perpendicular to the surface. As the height of the atomiser varies, the uniform ellipse moves linearly with it. With increasing atomiser-wall distance from 1.0 to $3.0 \mathrm{~m}$, the ellipse coverage varied from 0.65 to $2.04 \mathrm{~m}$ in height and from 0.48 to $1.64 \mathrm{~m}$ in width.

The spray duration does not have a significant affect on the area of coverage when the atomiser is perpendicular to the surface (see Figure 9(a)). However when the atomiser is angled at either $20^{\circ}$ or $45^{\circ}$ with respect to the perpendicular, there is an increase in surface area in relation to the spraying time (see Figure 9(b)). As the spray duration increases, some droplets lose their momentum and thus a spray cloud 'rolls' along the surface depositing very small droplets $(<15 \mu \mathrm{m})$ further along the surface. The small droplets that deposited further along the surface were low in volume and did not give complete coverage unless excessively long spray durations were used. In addition, the droplet sizes of these separated drops are so small that they evaporate very rapidly at the surface (30-60secs). This could affect the efficacy of the spray disinfection as the liquid contact time may prove to be too short to be effective for some solutions.

The spray pattern that is achieved with the atomiser set perpendicular to the surface is of a specific trend (see also Figure 9(a)). This tends to have a larger concentration of coalesced droplets in the centre with a rapid reduction in droplet sizes as one moves away from the centre towards the edge of the spray area.

Separate measurements were conducted by spraying onto a piece of dry porous absorbent material (i.e. sponge), on the predetermined area, at different required durations. This provided information on the percentage of the sprayed volume that is normally needed in order to have a uniform coverage area. These measurements showed that the central zone (area of uniform coverage, shown in Figure 9) comprised 25 percent of the sprayed volume and this remains in liquid form on the surface for several minutes, which is long enough to meet the chemical contact time of most treatment solutions.

It was found that some droplets deposited in a corner of the chamber, particularly when spraying at an angle to the wall, and even when spraying towards the centre of the wall. This deposition was additional to the expected spray pattern shown in Figure 9 and in the form of a narrow band of small droplets, as illustrated in Figure 10, that rapidly increased in 


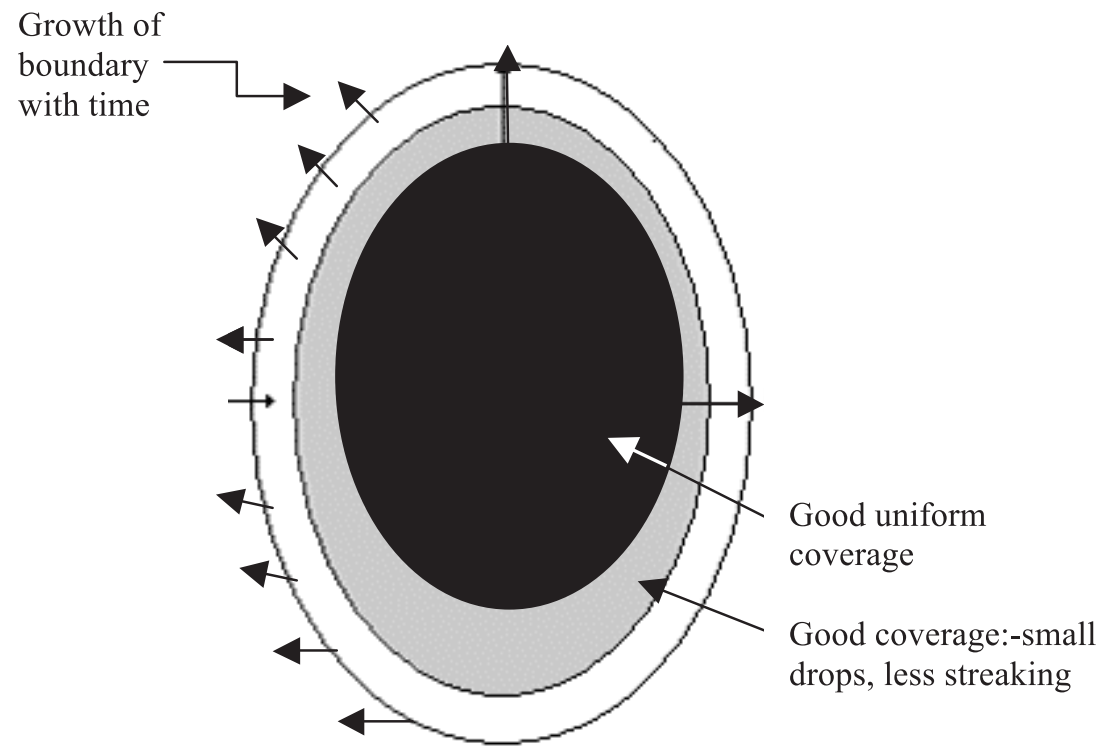

(a)

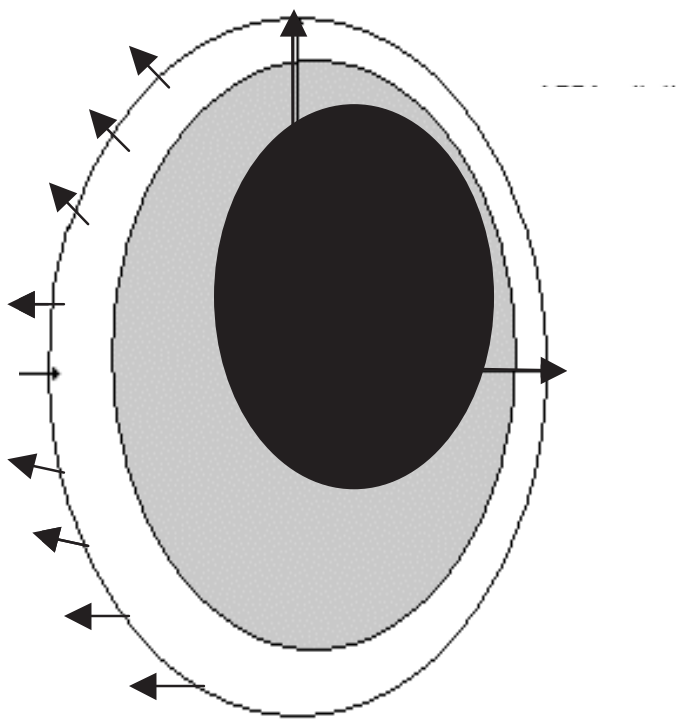

(b)

Figure 9. Schematic diagram of density of impacted drops for an atomiser (a) perpendicular to the wall and (b) at 30 degree to the perpendicular to the wall, diameters: $0.3 \mathrm{~mm}$ orifice and $0.5 \mathrm{~mm}$ spill, liquid flow rate: $0.245 \mathrm{l} / \mathrm{min}$ and supply pressure: $9 \mathrm{MPa}$ 


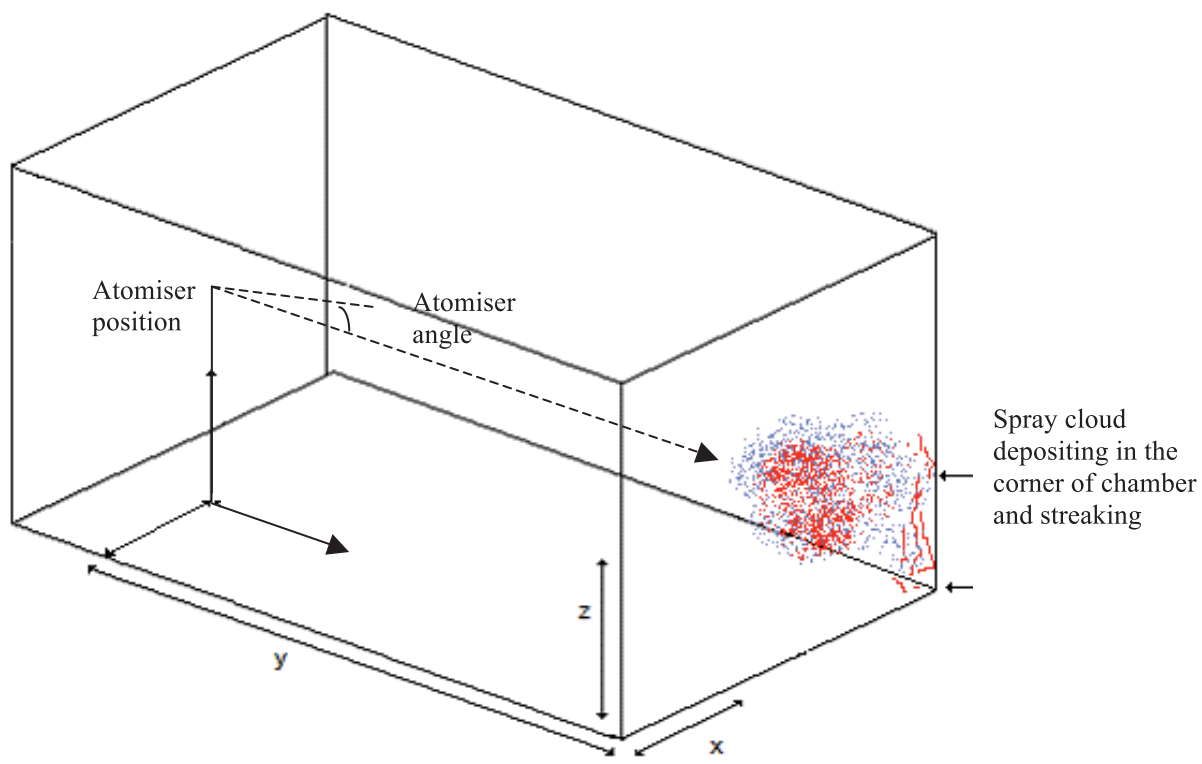

Figure 10. Test chamber showing spray deposition in the corner with the atomiser at an angle

concentration and caused streaking and subsequent deposition on the floor. This phenomenon is likely to be due to the Coanda effect enhanced by the $3 \mathrm{D}$ air circulation patterns induced in the chamber.

Figure 11(a) shows the deposition of the two spray areas by two atomisers on the test chamber wall. The results showed the two areas produced are each individually approximately 50\% smaller than the area for one atomiser, as illustrated in Figure 11(b). It was also noted that as the distance of the two atomisers is increased from the surface the area increases but at a declining rate. This was due to overlapping and the enhanced entrainment of air between the two sprays, particularly at further distances where the spray widths increases.

Figure 12 shows that for a spill orifice diameter of $0.5 \mathrm{~mm}$ the largest areas of good coverage are typically produced at a distance around $2.0 \mathrm{~m}$ from the surface. It was observed that at this distance although the width of the spray is high and droplets have decelerated, they still have enough momentum to reach the wall and be deposited without bouncing and without overspray. Referring to Figure 12, it is also important to note that at $2 \mathrm{~m}$ height; the coverage area is less when the distance is less than $2 \mathrm{~m}$ whereas it is more when the distance is greater than $2 \mathrm{~m}$. As the height, however, is increased to $3 \mathrm{~m}$, then even in the region beyond $2 \mathrm{~m}$ distance, it is not possible to produce a uniform or substantial coverage area with distance from the wall as the droplets momentum gradually tends to diminish.

It should be noted that by necessity this investigation used stationary atomisers, whilst in practice the normal method of application could be by slow manual traversing of spray across the walls and other surfaces. This means that dilute spray coverage area, of smaller droplets, that are outside the measured uniform coverage area, are not in fact completely wasted and they form an initial coverage of the surface that is completed when the main body of the spray is moved to this dilute coverage area. 


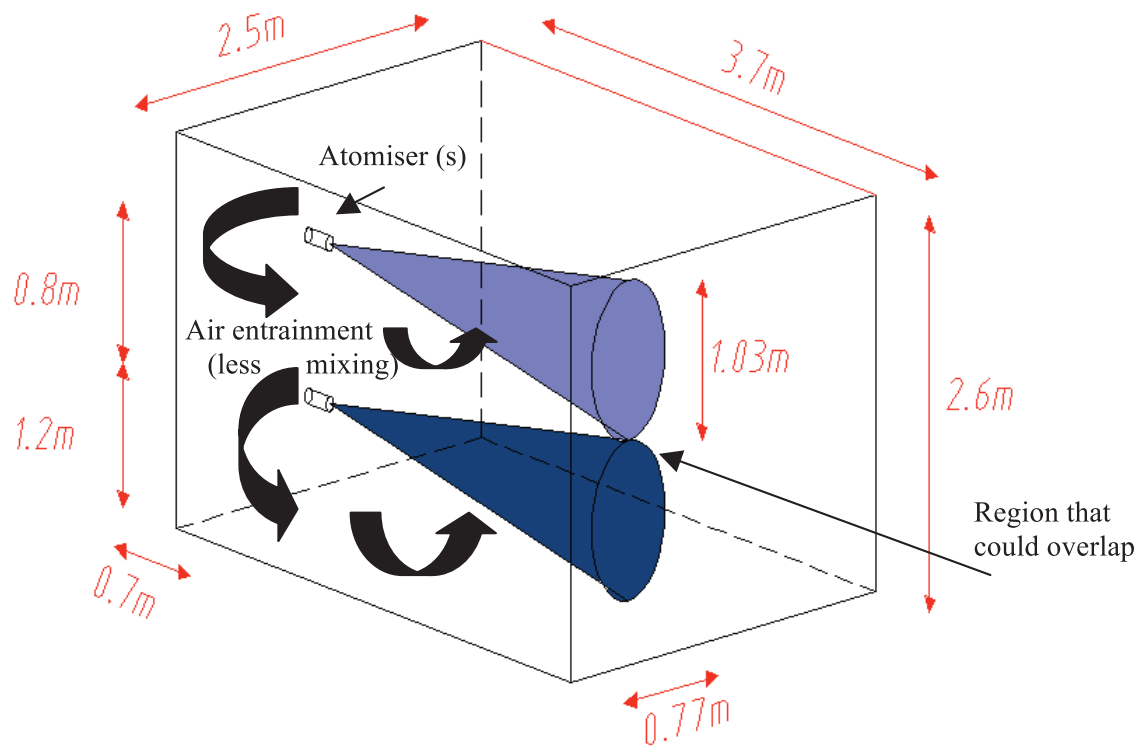

(a)

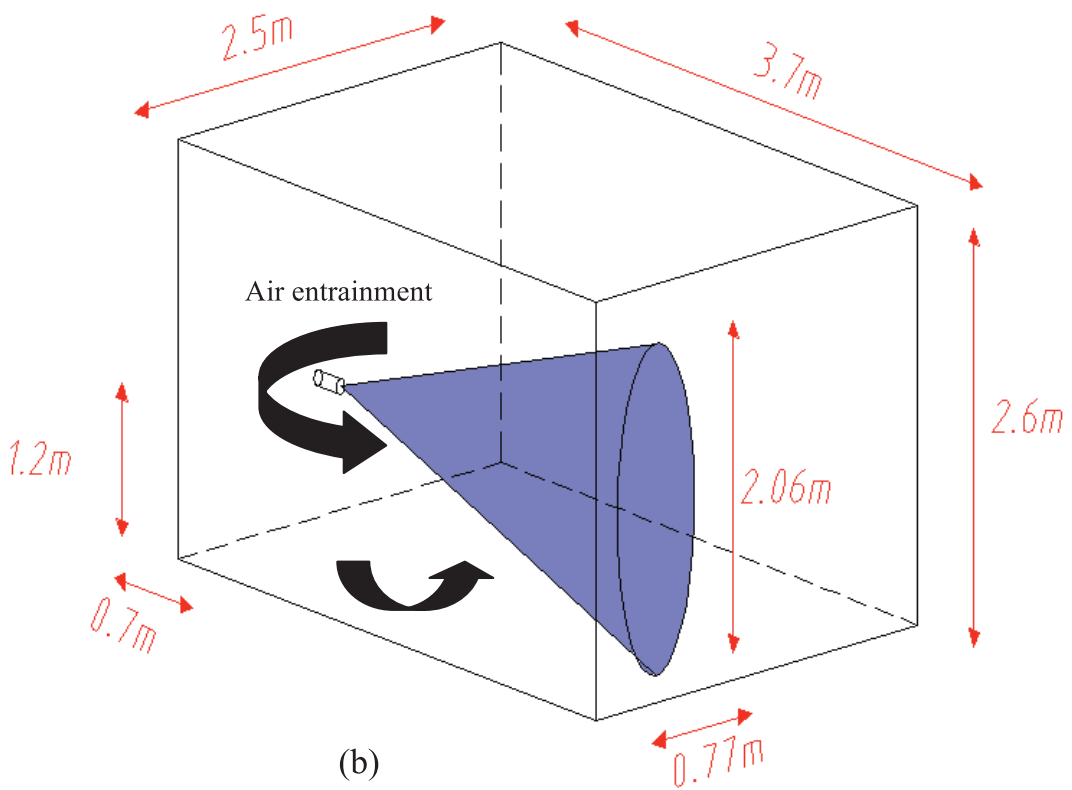

Figure 11. Test chamber showing spray deposition for two atomisers (a) and single atomiser (b) (Diameters: exit orifice $0.3 \mathrm{~mm}$, spill $0.5 \mathrm{~mm}$, flow rate: $0.245 \mathrm{l} / \mathrm{min}$ and supply pressure 9MPa) 


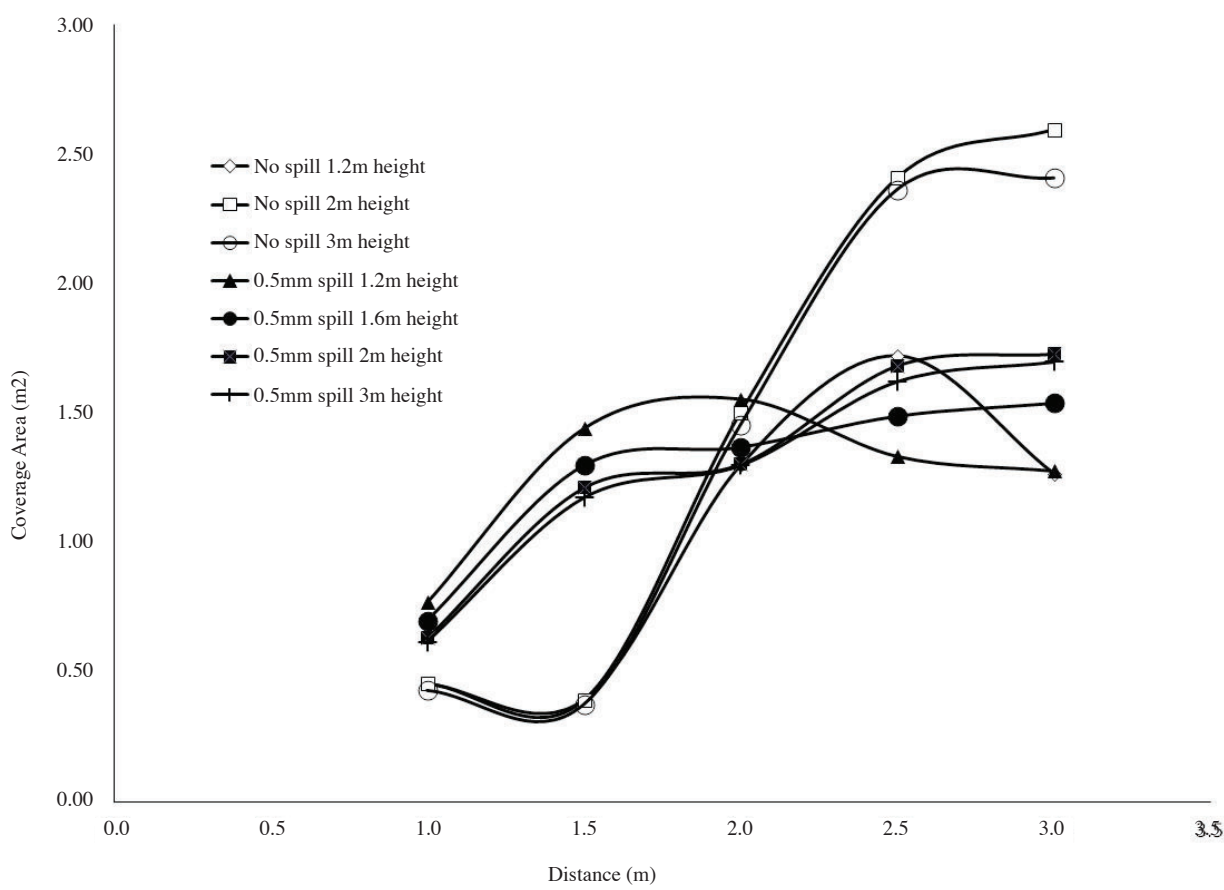

Figure 12. Effect of distance on coverage area for $0.5 \mathrm{~mm}$ spill orifice and no spill orifice at supply pressure $9 \mathrm{MPa}$ and flow rate $0.245 \mathrm{l} / \mathrm{min}$.

Figure 13 shows some comparisons with results using the current HSS disinfection equipment using the ultrasonic gas atomiser. Both systems were made to spray onto various surfaces over a distance of 1.0 to $3.0 \mathrm{~m}$ at the two heights of 1.2 and $2.0 \mathrm{~m}$ for required durations. It found that the swirl atomiser produced a larger average surface coverage area of typically $1.5 \mathrm{~m}^{2}$ compared to the ultrasonic atomiser average area of $1.0 \mathrm{~m}^{2}$. With the size of test chamber wall surface area $37 \mathrm{~m}^{2}$, it was found that for the swirl atomiser, 0.73 litres of liquid over a period of 17 minutes was required for complete disinfection of the chamber as opposed to 0.92 litres of liquid over 20 minutes using the ultrasonic atomiser.

The better performance of the spill-return swirl atomiser are that the narrower drop size distribution reduces drift and drop "bounce", caused by very small drops, whilst producing similar sizes of larger drops. It is believed that all the disinfection systems which are currently available cannot offer a fully efficient service. The delivery system, however, that proposed here using SRA has been rigorously tested and can offer many advantages over all current systems. To exemplify, in 2007, over 120 disinfection systems were offered to the government in the United Kingdom as a means to combat HAI-related problems. However, only two trolley-based systems were selected for clinical trials. Even the two chosen systems were rejected on the grounds that they could not perform to a satisfactory level and also all wards had to be evacuated with all furniture removed in order to complete the disinfection process effectively. The evacuation process was reflected in the high cost, inconvenience to patients and relatively large amount of time taken to achieve 'full coverage'. In contrast, the present in-situ fine spray disinfection mobile unit can effectively applies the spray onto an object or the surface with an adequate contact time and substantial coverage area. There is also no need for patient evacuation or removal of the related hospital equipment in the room or the ward or causing inconvenience to patients. 


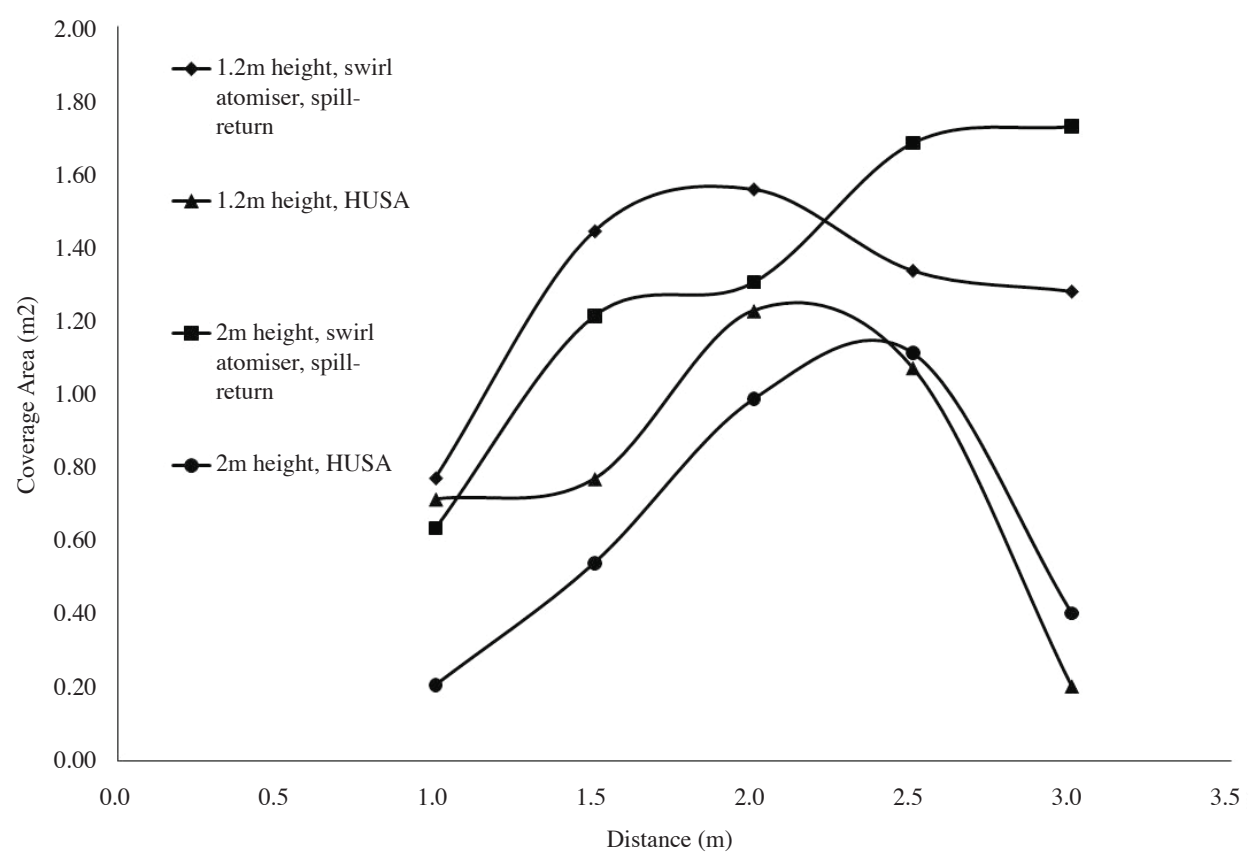

Figure 13. Effect of distance on coverage area using swirl atomiser (Diameters: exit orifice $0.3 \mathrm{~mm}$, spill $0.5 \mathrm{~mm}$ ) and Hughes Ultrasonic Atomiser (HUSA) on a plastic (PVC) surface

The current requirement for a potential new disinfection system is therefore extremely urgent. Current methods of cleaning within the health services, which leaves open the potential for hospital acquired infections to develop, is simply ineffective and dangerous. Bacteria are the major cause of HAIs within healthcare environments and therefore of the largest concern to be dealt with. This is mainly down to the vast numbers and variations of bacteria within any environment [13-22] and their ability to adapt to varying conditions including temperature and moisture levels and then pass this adaptation onto other bacterium.

\section{CONCLUSIONS AND FUTURE WORK}

The investigation has found that the utilisation of fine sprays $\left(10 \mu \mathrm{m}>D_{32}>25 \mu \mathrm{m}\right)$ at high liquid pressure $(<12 \mathrm{MPa})$ and low flow rates $(<0.3 \mathrm{l} / \mathrm{min})$ is suitable for surface disinfection in healthcare applications (i.e. MRSA, VRSA etc). The sprays from the new high pressure small spill return swirl atomisers are in some aspects superior to the current ultrasonic system for this application. A stand-off distance of $2.0 \mathrm{~m}$ with a $0.3 \mathrm{~m}$ exit orifice and $0.5 \mathrm{~mm}$ spill orifice diameter, give good coating conditions for supply pressures around 9.0MPa.

Future work will include spray coverage for ceilings and development of handheld devices using the results obtained here. Further development of the prototype system will also include trials for disinfection in actual healthcare environments (i.e. hospitals).

Mathematical mapping of the droplet impaction phenomena will also formulated, which could be used to predict the coating performance of a range of sprays. This mathematical mapping could also be utilised in the study of other spray coating applications, such as paint coating and combustion processes. 


\section{ACKNOWLEGMENT}

The authors wish to thank DTI (Department of Trade and Industry) for their financial support under the KTP (Knowledge Transfer Partnership) scheme and Hughes Safety Showers Ltd for the duration of the project

\section{REFERENCES}

1. Butler D. MRSA Action UK hails a major breakthrough in the battle against superbugs. Politics.co.uk. 2010. Accessed November, 2011.

2. Jennings K., Can the law help Hewitt take MRSA to the cleaners, Health Service Journal: Article on Infection Control, www.hsj.co.uk, 30 June 2005, Accessed 30 July 2005.

3. Plowman, R., Graves N., Griffin M., Roberts J.A., Swan A.V., Cookson B., The socio-economic burden of hospital acquired infection, Public Health Laboratory Service, 1999.

4. Nasr G.G., and Yule A.J., Spray device, Patent, WO 2008/075063 A1, 26 June 2008.

5. Nasr G.G., Yule A.J., and Lloyd S.E., The characterisation of the spray from a new and novel design of spillreturn swirl atomiser, Proceedings of the 21st ILASS-Europe Conference, Malaga University, Turkey 2007.

6. www.homelandsec.com/hs-p0/hs-p0075.cfm - Information relating to the use of fine spray systems in CBRN.

7. http://www.hughes-safety-showers.co.uk.

8. Nasr G.G., Yule A.J., Stewart J.A., Whitehead A., Hughes T., A New fine spray spill-return swirl atomiser, Journal of Mechanical Engineering Science, Proceedings of Institution of Mechanical Engineers Part C, Vol 225, August 2010.

9. Nasr G.G., Yule A.J. and Hughes T., The utilisation of fine sprays for Chemical, Biological, and Radiological or Nuclear (CBRN), Int Journal of Multi-phys, pp 61-72, Vol 3, 2009.

10. Yule A.J. and Widger I.R., Swirl atomisers operating at high water pressure, Int J Mech Sci, 38, Nos 8-9, 981999, 1996.

11. Nasr G.G., Yule A.J., and Bendig L., Industrial sprays and atomization, Springer Verlag, 2002.

12. Bai C.X., and Gosman A.D., Development of a methodology for spray impingement simulation, SAE Paper 950283, 1995.

13. MaD.G., Alvarado C.J., Hassemer C.A., Zilz M.A., Relation of the inanimate hospital environment to endemic mosocomial infection, New Eng. J .Med. no. 307, pp1562-1566, 1982.

14. Blythe D., Keenlyside D., Dawson S.J., Galloway A. Environment contamination due to MRSA, J Hosp Infec no.38, pp 67-70, 1998.

15. Wilkinson S.M., Effect of infection control measures on skin of healthcare workers, Comm Dis Public Health, pp 305-6, 2000.

16. Health care infection control practices advisory committee and hand-hygiene task force, Society for Healthcare Epidemiology of America, Association for Professional in Infection Control and Equipment, Infection Diseases Society of America. Guideline for hand hygiene in healthcare settings, J Am Coll Surg No. 198, pp 121-7, 2004.

17. Rao G. A study to identify and determine the significance of attributional bias in the control and prevention of MRSA, National Nursing Research Unit, 2007.

18. Menuet D., Verachten M., Girou E., Comparison of the efficacy of a hydrogen peroxide dry-mist disinfection system and sodium hypochlorite solution for eradication of Clostridium difficile spores., National Reference Laboratory for Clostridium difficile, Hospital Saint-Antoine, Assistance Publique-Hôpitaux de Paris, Paris, Infect Control Hosp Epidemiol:;30(6):507-14, 2009 Jun

19. Falagas M.E., Thomaidis P.C., Kotsantis I.K., Sgouros K., Samonis G., Karageorgopoulos D.E. , Review Airborne hydrogen peroxide for disinfection of the hospital environment and infection control: a systematic review. J Hosp Infect. 2011 Jul; 78(3):171-7. Epub 2011 Mar 9.

20. Debreceni1 G., Meggyesi R. and Mestyan G., Efficacy of spray disinfection with a 2-propanol and benzalkonium chloride containing solution before epidural catheter insertion-a prospective, randomized, clinical trial, British Journal of Anaesthesia 98 (1): 131-5 , 2007. 
21. Sui YS, Wan GH, Chen YW, Ku HL, Li LP, Liu CH, Mau HS., Effectiveness of Bacterial Disinfectants on Surfaces of Mechanical Ventilator Systems. Respir Care. Jul 12, 2011.

22. LI Zi-yao, CUI Shu-yu, ZHAO Ke-yi, WEN Xian-qin, Meng Wei, Liu Wen-jie, comparison of disinfection of efficacy on different microorganism aerosol, Shangdong Provincial Center for Disease Prevention and Control, Jinan 250014, Chinese J Disinfection, 28(1), 2011, China

\section{NOTATION}

$\mathrm{D}_{32}$ (SMD) The diameter of the drop whose ratio of volume to surface area is the same as that of the entire spray.

HUSA Hughes Ultrasonic Atomiser 